\title{
CULTURA DE SEGURANÇA DOS ALIMEN- TOS: CONCEITO E ELEMENTOS PARA A PRÁTICA DOS PROFISSIONAIS QUE ATUAM EM EMPRESAS DO SETOR ALIMENTAR
}

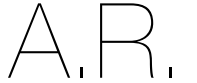
ARTIGO DE REVISÃO

1 Universidade Federal do Rio Grande do Sul, Rua Ramiro Barcelos, 2400 - CEP 90035-003 Porto Alegre, RS - Brasi

2 Universidade Federal de São Paulo,

Rua Botucatu, 862 - CEP 04023-062 - São Paulo, SP - Brasil

"Endereço para correspondência:

Janaína Venzke

Rua Ramiro Barcelos,

Alegre RS - Brasi

janaina.venzke@ufrgs.br

Histórico do artigo:

Recebido a 10 de março de 2021 Aceite a 3 de setembro de 2021

\section{FOOD SAFETY CULTURE: CONCEPT AND ELEMENTS FOR THE PRACTICE OF PROFESSIONALS WORKING IN FOOD COMPANIES}

Júlia Bregolin'; Laís Zanin²; Elke Stedefeldt²; Janaína Venzke'

RESUMO

As doenças de origem alimentar são preocupações mundiais de saúde pública e as suas causas possuem relação direta com processos inadequados de boas práticas de higiene. O fortalecimento do conceito da cultura de segurança dos alimentos e a modificação positiva da cultura de uma determinada empresa do setor alimentar estão relacionadas com a possibilidade de diminuição do risco de doenças de origem alimentar. O objetivo do estudo foi identificar, por meio de uma revisão narrativa, o conceito e os elementos da cultura de segurança dos alimentos e aproximar o tema à prática profissional dos responsáveis que atuam em empresas do setor alimentar. A cultura de segurança dos alimentos é o conjunto de atitudes, valores e crenças aprendidas e partilhadas, que contribuem para os comportamentos de higiene num ambiente de preparação e distribuição de alimentos. Os seus principais elementos são: sistemas de gestão, liderança, comunicação, compromisso, ambiente e perceção de risco.

\section{PALAVRAS-CHAVE}

Ambiente de Trabalho, Comunicação, Inocuidade dos alimentos, Liderança, Nutrição, Serviços de alimentação

\section{ABSTRACT}

Foodborne diseases are a global public health concern and the causes are directly related to inappropriate food-handling practices. The understanding of food safety culture concept and the positive culture modification of a given food service are related to the possibility of reducing the risk of foodborne diseases. The purpose of this study was to present through a narrative review the concept and elements of food safety culture and to approach the theme to the professional practice of people who are responsible for food services. Food safety culture is the aggregation of learned and shared attitudes, values and beliefs contributing to the hygiene behaviors in a particular food-handling environment. Its main elements are management systems, leadership, communication, commitment, environment, and risk perception.

KEYWORDS

Working Environment, Communication, Food safety, Leadership, Nutrition, Food service

\section{INTRODUÇÃO}

As doenças de origem alimentar causadas por bactérias, vírus, parasitas ou substâncias químicas, afetam a cada ano, em todo o mundo, cerca de 600 milhões de pessoas, resultando em 420 mil mortes e na perda de 33 milhões de anos de vida saudáveis, atingindo indivíduos de todas as idades, particularmente crianças menores de cinco anos de países em desenvolvimento (1). No entanto, a nível mundial, dados relacionados a surtos alimentares são apenas estimativas, em função da subnotificação de casos (2). Isso deve-se ao facto de somente uma fração dos casos relacionados com ingestão de alimentos impróprios para consumo ser documentada e notificada às autoridades de saúde pública e registadas nas estatísticas oficiais de doenças $(1,3)$.

As doenças de origem alimentar são uma das importantes causas de morbilidade e mortalidade, além de um impedimento significativo para o desenvolvimento socioeconómico em todo o mundo. Fatores como água contaminada usada para a higienização e processamento de alimentos, ausência de infraestruturas adequadas de armazenamento e processos impróprios de produção e manipulação de alimentos contribuem significativamente para um ambiente que favorece a ocorrência de doenças de origem alimentar (2). Assim sendo, é indispensável valorizar a importância das boas práticas de higiene e da formação continuada dos colaboradores de empresas do setor alimentar, fortalecendo uma cultura positiva de segurança dos alimentos e visando a prática de processos para uma produção segura de alimentos (4).

Em 2020, a nível internacional, o Codex Alimentarius (4) recomendou a abordagem da cultura de segurança dos alimentos na atualização dos Princípios Gerais da Higiene dos Alimentos (CXC 1-1969). No mesmo sentido, a nível da União Europeia, o Regulamento (UE) 2021/382, de 3 de março de 2021, veio alterar o Regulamento (CE) n.o 
852/2004 apresentando a exigência de que as empresas do setor alimentar devem estabelecer, manter e apresentar elementos de prova relativos a uma cultura de segurança dos alimentos adequada (5). Além disso, referenciais normativos de requisitos para obtenção de certificação como a Food Safety System Certification 22000 (6) e a British Retail Consortium (7) começaram a introduzir a necessidade da abordagem da cultura de segurança dos alimentos.

$\mathrm{O}$ arcabouço regulatório que fundamenta e determina os processos de boas práticas de higiene, mesmo abordando inúmeros fatores, nem sempre é suficiente para melhorar o desempenho relativamente à segurança dos alimentos em empresas do setor alimentar. Para alcançar tais melhorias são necessários outros processos, iniciando pelo mais complexo - a transformação positiva da cultura de segurança dos alimentos, que exige a compreensão da cultura organizacional e das dimensões humanas que impactam na segurança dos alimentos. Desta forma, além de atividades de verificação, monitorização e formação de manipuladores de alimentos, o objetivo dos responsáveis pela segurança dos alimentos também deve incluir a avaliação e a transformação da cultura de segurança dos alimentos, na qual outros fatores são intrínsecos, como a influência e mudança do comportamento humano (8).

De acordo com Griffith et al., um dos primeiros autores a definir este fenómeno, a cultura de segurança dos alimentos é o conjunto de atitudes, valores e crenças aprendidas e partilhadas, que contribuem para os comportamentos de higiene num ambiente de preparação e distribuição de alimentos (9). Nesse sentido, em conformidade com o Regulamento da União Europeia 2021/382, para a abordagem da cultura de segurança dos alimentos é necessário que os colaboradores do setor alimentar, no papel da gestão, assegurem que as funções e responsabilidades sejam claramente comunicadas, mantenham a integridade do sistema de higiene dos alimentos, verifiquem se os controlos são realizados, assegurem que os colaboradores recebam formação adequada, garantam a conformidade com os requisitos regulamentares e incentivem a melhoria do sistema de gestão de segurança dos alimentos da organização (5).

Outros conceitos da cultura de segurança dos alimentos também foram apresentados pela literatura, como a definição da Iniciativa Global de Segurança dos Alimentos, que a define como "valores compartilhados, crenças e normas que afetam o pensamento e o comportamento em relação à segurança dos alimentos em, através, e por toda a organização" (10). Recentemente, um novo conceito sobre cultura de segurança dos alimentos foi considerado, definindo-a como uma construção de longo prazo existente no nível organizacional, relacionada com as crenças, comportamentos e premissas profundamente enraizadas que são aprendidas e compartilhadas por todos os funcionários e que impactam no desempenho de segurança dos alimentos da organização (11).

É importante diferenciar o conceito de segurança dos alimentos em relação ao conceito de clima. O clima de segurança dos alimentos é definido como uma construção temporária existente a nível individual, relacionando a perceção e as atitudes dos indivíduos e como eles influenciam outros numa organização a aderir ao sistema de gestão de segurança dos alimentos e aplicá-lo de forma prática no seu ambiente de trabalho (11).

Em função do número significativo de doenças de origem alimentar refletir processos inadequados de boas práticas de higiene e fabrico, ressalva-se a necessidade de um olhar diferenciado às empresas do setor alimentar. A cultura de segurança dos alimentos é um tema relativamente recente quando se trata de segurança dos alimentos. Nesse sentido, é pertinente explorar os diferentes elementos que permeiam a cultura de segurança dos alimentos por meio de um exercício reflexivo na literatura científica com o propósito de estabelecer estratégias para diminuir o risco de doenças de origem alimentar.

Desta forma, esta revisão tem o propósito de aproximar o conceito de cultura de segurança dos alimentos aos profissionais que atuam em empresas do setor alimentar, por meio da discussão dos elementos que a compõem e das suas estratégias.

\section{METODOLOGIA}

A revisão narrativa foi realizada no período de março a junho de 2018 e atualizada em agosto de 2021, a fim de integrar documentos de referência e novos artigos publicados nos últimos anos, utilizando as bases de dados científicas Google Académico, ScienceDirect, Web of Science, Scopus e Lilacs. A pesquisa baseou-se na pergunta: De que forma a apropriação da cultura de segurança dos alimentos e dos seus elementos pode auxiliar a realização de práticas seguras? Os seguintes descritores foram utilizados em inglês e em português: food safety culture, food safety, culture, systems management, communication, leadership e risk perception, inocuidade dos alimentos, serviços de alimentação, comunicação, liderança, ambiente de trabalho e nutrição, respetivamente. Foram incluídos nesta revisão narrativa artigos originais, de revisão, guias e livros, sem limitação de data, país do estudo ou área do conhecimento, bem como referenciais normativos. A Figura 1 apresenta o diagrama do processo de seleção dos artigos pesquisados para esta revisão.

\section{A Cultura de Segurança dos Alimentos no Contexto das Organizações}

A cultura por si só, dentre as suas inúmeras definições conforme determinado contexto, pode ser descrita como um conjunto de pensamentos e comportamentos semelhantes que caracterizam um grupo social, sendo capaz de ser incorporada por meio da socialização e perdurar ao longo do tempo (12). Inserido nesse contexto, um dos conceitos-chave, segundo Taylor, é o de uma "experiência partilhada", na qual as pessoas se reúnem a partir destas ideias e experiências em comum, havendo a possibilidade de ser desenvolvida de forma consciente ou não, mas que de qualquer forma irá caracterizar certo grupo (13).

Considerando a cultura no contexto de uma organização, Schein, um dos pioneiros da dimensão da cultura organizacional, aborda esse tema como o resultado de um conjunto de aprendizagens adquiridas em momentos destinados à resolução bem-sucedida de problemas (14). Nesse sentido, os sujeitos envolvidos no processo de aprendizagem acreditam que as abordagens utilizadas para resolver os problemas são o direcionamento correto e retransmitem a maneira de pensar, sentir e agir a todos os membros $(14,15)$. Além disso, outros autores $(16,17,18)$ também procuraram definir o termo cultura organizacional, enfatizando combinações diversas de fatores de uma organização, como tradição, filosofias partilhadas, regras, comunicação e sistemas de controlo (9).

A partir da cultura organizacional e da cultura de segurança, conforme descrito por Nyarugwe et al., a cultura de segurança dos alimentos emergiu como novo campo de estudos (19). Nesta perspetiva, é possível relacionar a cultura nacional e organizacional à produção dos alimentos, uma vez que a cultura de segurança dos alimentos é determinante para a criação e implementação do sistema de gestão de segurança dos alimentos do local. A cultura de segurança de uma organização é o produto dos valores, atitudes, competências e padrões individuais e de grupo que determinam o compromisso a programas de saúde e segurança de uma organização $(20,21)$. 
Diagrama do processo de inclusão e exclusão dos artigos para a revisão narrativa

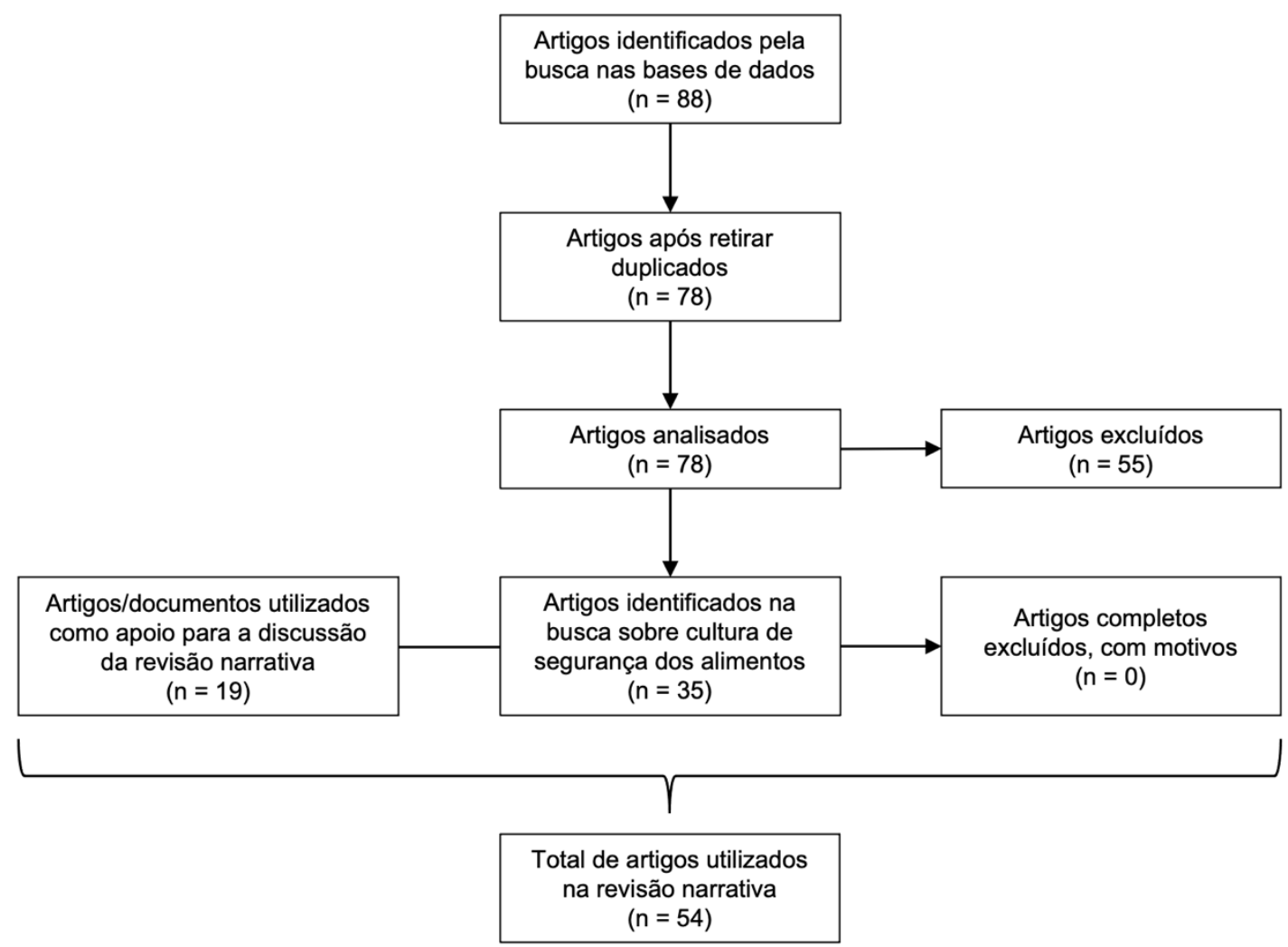

É consensual que a cultura de uma organização tem grande influência na maneira como os indivíduos pensam, veem e agem em relação à segurança (8).

De acordo com Griffith (22) alguns preceitos são importantes para o entendimento da cultura de segurança dos alimentos, como: todas as empresas do setor alimentar têm uma cultura de segurança dos alimentos, seja ela conhecida ou desconhecida; a cultura pode ser positiva, favorecendo a implementação das boas práticas de higiene, neutra, quando não se tem conhecimento sobre ela, ou negativa, na qual ela não é considerada importante e é substituída por outras necessidades, como questões financeiras. A cultura de segurança dos alimentos, se partilhada dentro de um grupo, incorpora aspetos individuais; quando um novo funcionário é admitido, mesmo que as suas crenças sobre segurança dos alimentos sejam diferentes, este pode-se adaptar e incorporar as práticas do novo local de trabalho (22). De acordo com o Regulamento da União Europeia 2021/382 relativo à higiene dos géneros alimentícios (5), a transformação da cultura de segurança dos alimentos deve levar em consideração a natureza e a dimensão da organização. Inseridos na cultura de segurança dos alimentos, existem alguns elementos que auxiliam na compreensão, na avaliação e na transformação da cultura organizacional. Griffith et al. (23) indicam que a cultura de segurança dos alimentos é composta por seis elementos, sendo eles: sistemas de gestão, liderança, comunicação, comprometimento, ambiente e perceção de risco. O Regulamento da União Europeia 2021/382 e o Codex Alimentarius levam em consideração os requisitos: compromisso da gestão, liderança, comunicação, sensibilização em relação aos perigos e disponibilidade de recursos $(4,5)$. Estes requisitos vão ao encontro do que é proposto por Griffith et al. (23). Há, ainda, outros autores que propõem elementos e dimensões para a cultura de segurança dos alimentos que não serão tratados nesse artigo (10, 24-26).
A compreensão destes elementos e o seu impacto na minimização dos riscos de doenças de origem alimentar podem direcionar ações para a atuação dos profissionais das empresas do setor alimentar responsáveis pelas boas práticas de higiene, objetivando o fortalecimento da cultura de segurança dos alimentos positiva no local de interesse e, portanto, a diminuição dos surtos de doenças de origem alimentar (23).

\section{Sistemas de Gestão}

Os sistemas de gestão definem como o trabalho de uma organização é realizado e a gestão visa atingir metas através do planeamento, da organização, do pessoal e da direção dos recursos (27). De acordo com Griffith, o sistema de gestão de segurança de alimentos pertence à gestão de qualidade (22), que procura garantir e controlar que todos os processos necessários sejam executados de maneira efetiva (28). Consiste em decisões orientadas para objetivos que resultam em atividades que contribuem para atender ou mesmo exceder os requisitos de qualidade de clientes e consumidores (29). Portanto, compreender de forma geral um determinado serviço de alimentação, quais os cargos e funções que o compõem, como se encontra estruturado e quais os sistemas de qualidade que estão implementados são atividades essenciais para avaliar a cultura de segurança dos alimentos e projetar melhorias.

Devido à especificidade das legislações nacionais, regionais e locais, os sistemas de gestão da segurança alimentar podem ser elaborados de maneira distinta, resultando também num desempenho variável $(30,31)$. Dificilmente haverá um modelo que se adeque a todas as empresas do setor alimentar (23). Um sistema de gestão da segurança alimentar deve conter uma política geral de funcionamento clara e definida, composta por objetivos que irão guiar a organização à visão pretendida (32). 
Outra característica importante para o sistema de gestão de segurança de alimentos é a compreensão de que cada pessoa e processo interagem e influenciam outras pessoas e outros processos. Portanto, um sistema de gestão eficiente requer: 1) a comunicação por meio de momentos de orientação e reuniões; 2) medidas e controlo de metas; 3) reforço constante das orientações nas atividades de formação e educação. Essas ações irão refletir-se em trabalhadores motivados para a produção de alimentos seguros e confiáveis $(33,34)$.

\section{Liderança}

A partir de um sistema de gestão de segurança dos alimentos estruturado e organizado, lideranças proativas são o alicerce para a sua realização $(23,35)$. A positividade da cultura de segurança dos alimentos de uma organização é o reflexo direto do envolvimento e comprometimento dos líderes com a segurança dos alimentos. A cultura de segurança dos alimentos é uma responsabilidade partilhada, mas são os líderes os maiores responsáveis por fortalecer e sustentar esta cultura de forma positiva, estando a equipa de gestão diretamente ligada a essa função (8).

Os estilos de liderança, o clima organizacional e a conformidade dos colaboradores com a segurança dos alimentos e os comportamentos de higiene estão positivamente correlacionados. O clima organizacional tem um efeito mediador completo entre o estilo de liderança, as boas práticas de higiene e fabrico e a segurança dos alimentos. Nesse sentido, os colaboradores que atuam em empresas do setor alimentar podem aumentar o cumprimento dos comportamentos relacionados à higiene e segurança dos alimentos através do efeito mediador do clima organizacional (36).

De maneira geral, todas as empresas do setor alimentar necessitam de bons líderes e, na prática, qualquer trabalhador pode ser um líder. A liderança surge do conhecimento atualizado, da confiança, das competências interpessoais e não de um cargo específico. Para isso, é necessário trabalhar algumas questões pessoais, como tolerância ao stresse, autoconfiança, autocontrolo, estabilidade emocional, empatia e motivação para a gestão $(37,38)$. De forma prática, é essencial que líderes exponham com clareza os objetivos e as expectativas em relação à segurança dos alimentos; influenciem positivamente e motivem a equipa para a realização de práticas seguras; ouçam as considerações e opiniões dos colaboradores por meio de conversas construtivas e respeitadoras; tenham metas alinhadas com a instituição; e procurem o contínuo desenvolvimento do grupo e da cultura de segurança dos alimentos (35).

\section{Comunicação}

A comunicação, vista concomitantemente como causa e solução das não conformidades relacionadas à segurança dos alimentos, também deve ser levada em consideração para a cultura de segurança dos alimentos. Num serviço de alimentação, à medida que as metas e práticas são definidas, estas precisam ser comunicadas pelos profissionais de forma eficiente para serem compreendidas pela equipa (39).

Diálogos informais, como conversas durante o trabalho, podem ter um maior impacto no comportamento e podem deixar os manipuladores mais recetivos à informação, quando comparados com comunicações formais, a exemplo dos e-mails (23). Se o objetivo for manter a equipa sempre informada sobre as boas práticas de higiene, utilizar meios variados de comunicação aumenta a adesão e passa a fazer parte da cultura do local. Nesse sentido, pósteres, símbolos e slogans devem conter mensagens específicas, simples, claras, objetivas e devem ser inseridas num local adequado para que façam sentido (8).
Se a ideia for produzir materiais audiovisuais para a equipa, como vídeos educativos, a presença de indivíduos com características semelhantes às de quem irá assistir aumenta as possibilidades de conexão, levando a uma maior influência sobre os pensamentos, atitudes e comportamentos dos colaboradores.

Em relação aos acordos sobre mudanças de comportamentos, estudos demonstram que acordos escritos quando comparados com verbais tendem a ser mais efetivos, fazendo com que as pessoas se responsabilizem pelo que foi exatamente combinado (40).

A comunicação não-violenta, cujo objetivo é "estabelecer um relacionamento baseado na sinceridade e na empatia", pode auxiliar o profissional responsável pela segurança dos alimentos na condução de conversas e das formações. O conceito envolve expressar-se honestamente por meio de factos, sentimentos, necessidades e pedidos e, ao ouvir alguém, receber o que está a ser dito com empatia (41).

\section{Comprometimento}

Se a cultura de segurança dos alimentos é o reflexo dos valores de uma organização, a sua positividade também é o reflexo das escolhas de estratégias para a transformação cultural $(8,42)$. Nesse contexto, os líderes têm um papel fundamental na manutenção da cultura de segurança dos alimentos positiva e são vistos como exemplos para os restantes colaboradores. É o que eles fazem e não o que dizem que de facto irá influenciar a equipa, refletindo-se diretamente no comprometimento e na motivação dos manipuladores de alimentos (43). Como a cultura de segurança dos alimentos é considerada responsabilidade de todos, a sua manifestação é resultado de um trabalho em conjunto no qual gestores, colaboradores e todos os manipuladores de alimentos devem estar reunidos nas diferentes etapas do processo (23).

Na prática, é possivel realizar ações de formação, como, por exemplo, encorajar os colaboradores a escreverem as suas responsabilidades em relação à segurança dos alimentos. Além disso, possuir um organograma de responsabilidades claro e exposto no serviço de alimentação pode ter um impacto positivo, uma vez que o colaborador visualiza o seu nome e as suas responsabilidades (8).

\section{Ambiente}

Um ambiente de trabalho adequado refere-se à oferta de estrutura e equipamentos em condições apropriadas para as atividades exigidas, além de um planeamento adequado para que os manipuladores de alimentos não sofram pressão pela carga de trabalho. Nesse contexto, além de se focar nas relações interpessoais e no modo como a segurança dos alimentos é abordada, também é primordial investir em fatores ambientais e físicos, como layout das instalações, equipamentos, utensílios e quadro de colaboradores em número suficiente $(8,23,35)$. Num estudo sociológico constatou-se que aspetos inerentes à conveniência e rapidez no trabalho, deficiência na infraestrutura, falta de funcionários, exemplos de comportamentos negativos dos líderes, exposição a ruídos e às dores corporais sentidas pelos colaboradores podem contribuir para o não cumprimento das boas práticas de higiene e se consolidar no habitus e sentido prático. Em consequência, estas disposições podem aumentar o risco de doenças de origem alimentar (44).

\section{Perceção do Risco}

Segundo Griffith, a perceção do risco compreende "os processos de julgamento e tomada de decisão que permitem aos indivíduos avaliar as possibilidades de serem afetados por determinado risco" (23). Diversas variáveis interferem na perceção do risco da população 
em geral, como crenças e convicções individuais sobre um risco em questão, sendo estas distintas quando comparadas com a visão de profissionais e especialistas, que tem como base factos e dados científicos (45).

As diferenças na perceção do risco dos manipuladores de alimentos podem estar relacionadas com as diversidades regionais, étnicas, socioeconómicas ou de género e têm implicações importantes para a prática de comunicação de risco (46). Dessa forma, a compreensão dos fatores que influenciam a avaliação sobre os riscos e a recolha de informações sobre perceções, crenças e conhecimentos do públicoalvo em questão auxilia o profissional responsável pela segurança dos alimentos a direcionar o diálogo sobre prevenção de doenças de origem alimentar e diminuição de riscos (47). Entende-se que a perceção do risco é permeada por ilusões cognitivas, como a presença do viés otimista, da ilusão de controlo, e do locus de controlo externo, sendo que muitos anos de serviço e/ou participação em várias formações ineficazes de boas práticas de higiene e fabrico podem gerar um excesso de confiança nos colaboradores, impedindo-os de agir adequadamente para minimizar o risco de doenças de origem alimentar (48).

Com fundamento em tais contextos, a partir do conhecimento sobre as crenças e convicções individuais e gerais dos manipuladores de alimentos, é necessário que o profissional responsável pela segurança dos alimentos adapte as informações e promova estratégias de educação para aumentar a perceção do risco dos manipuladores e a perceção da letalidade das doenças de origem alimentar (46, 49, 50). Alguns autores sugerem utilizar exemplos de situações reais em serviços de alimentação similares ao local $(8,50)$; não utilizar exemplos clichês e já rotulados; orientar o colaborador constantemente e não apenas em momentos destinados à educação; estimular a autorreflexão e reforçar as boas práticas de higiene de maneira positiva (50).

Na prática, a gerência pode utilizar como exemplo a história completa de uma única pessoa que tenha sofrido com doenças de origem alimentar a fim de melhorar a perceção do risco dos seus colaboradores. Resgatar esta situação sempre que possível pode ter mais impacto do que informar dados nacionais e mundiais relevantes (40).

\section{ANÁLISE CRÍTICA}

O fortalecimento da cultura de segurança dos alimentos e a utilização de estratégias baseadas em comportamento podem auxiliar a realização de práticas seguras em empresas do setor alimentar. Nesse contexto, melhorar o conhecimento, o comprometimento, a comunicação e a perceção do risco dos colaboradores por meio da liderança, do estilo de gestão e ambiente de trabalho adequados é favorável para a segurança dos alimentos (51).

Para o bom funcionamento de qualquer sistema de gestão de segurança dos alimentos, é fundamental a manutenção de uma cultura positiva de segurança de alimentos, reconhecendo a importância do comportamento humano no fornecimento de alimentos seguros e adequados (4).

De acordo com o Regulamento da União Europeia 2021/382 (5), alguns requisitos são indispensáveis para esta manutenção, como: compromisso da gestão e de todos os colaboradores; presença de liderança que conduza à produção de alimentos seguros e ao envolvimento de todos os colaboradores; sensibilização de todos os colaboradores em relação aos perigos e à importância da segurança dos alimentos; comunicação aberta e clara entre todos os colaboradores da empresa, incluindo a comunicação de desvios e expectativas; disponibilidade de recursos suficientes (5).

A presença de um profissional experiente responsável pela segurança dos alimentos, aliado a um sistema de gestão da segurança alimentar e aos valores da empresa, é uma estratégia para o fortalecimento da cultura de segurança dos alimentos. Para alcançar melhores resultados, os gestores devem aprimorar as recompensas e incentivos e aumentar a visibilidade e a transparência dos processos (51). Portanto, é imprescindível que os manipuladores compreendam o real significado e a importância dos processos para a garantia da segurança dos alimentos para que não os executem apenas em função das bonificações.

É função dos gerentes de unidades de alimentação verificar se os controlos são realizados em tempo útil e de forma eficiente e se a documentação está atualizada (5). Os gerentes de unidades de alimentação também devem considerar a pressão de trabalho, ou seja, o desgaste dos funcionários, a complexidade do trabalho, a motivação e a insatisfação, uma vez que esses fatores podem afetar a segurança dos alimentos e o clima de segurança dos alimentos $(51,52)$.

A chave para a liderança é ter uma visão de segurança dos alimentos combinada com metas, visão e missão da organização $(15,53)$, sendo possível desenvolver com a equipa indicadores de controlo que expressem a realidade das boas práticas de higiene e fabrico. Tais abordagens também podem ser consideradas na avaliação diagnóstica da cultura de segurança dos alimentos, que pode ser utilizada como ponto de partida para a formação dos manipuladores de alimentos (54). Dessa forma, é importante realçar que essas abordagens requerem um líder com conhecimentos técnicos suficientes para desenvolver e capacitar os colaboradores de um modo adequado à função que desempenham, objetivando a garantia da segurança dos alimentos. Uma comunicação adequada e eficiente reflete-se no nível de conhecimento dos manipuladores de alimentos. Portanto, a avaliação de conhecimentos pode indicar parâmetros que permitam avaliar a eficiência da comunicação (23). Em relação às formações com a equipa, estas devem ser focadas em questões práticas, que promovam melhor comunicação, clima, motivação e fortaleçam a cultura de segurança dos alimentos (51).

\section{CONCLUSÕES}

A compreensão da cultura de segurança dos alimentos e dos seus elementos pode auxiliar positivamente na implementação e/ou na promoção das boas práticas de higiene e fabrico, estando isso em consenso entre os autores. Fortalecer a cultura de segurança dos alimentos exige a sinergia de todos os elementos que exercem influência sobre a segurança dos alimentos e é um processo acompanhado por determinação, comprometimento e dedicação, o qual os colaboradores são capazes de executar se estiverem rotineiramente em contacto com os gestores responsáveis que atuam em empresas do setor alimentar. Esta investigação apoia a necessidade de formação dos profissionais para atuarem em empresas do setor alimentar considerando aspetos da cultura organizacional para além de processos produtivos. Espera-se que este artigo possa instigar a pesquisa pela perceção de fatores comportamentais, além de fatores técnicos para obtenção de alimentos seguros.

\section{REFERÊNCIAS BIBLIOGRÁFICAS}

1. World Health Organization: World Food Safety Day. 2020. Disponível em: https:// www.who.int/campaigns/world-food-safety-day/2020.

2. World Health Organization. WHO estimates of the global burden of foodborne diseases: foodborne disease burden epidemiology reference group 2007-2015. 2015. 3. Centers for Disease Control and Prevention (CDC). Surveillance Resource Center. Estimates of Foodborne lliness in the United States. 2018. Disponivel em: https://www. cdc.gov/foodborneburden/2011-foodborne-estimates.html. 
4. Codex Alimentarius International Food Standards. Princípios Gerais da Higiene dos Alimentos. CXC 1-1969, Rev. 3 - 2020. 2020. 36p. Disponível em: http://www.fao. org/fao-who-codexalimentarius/codex-texts/codes-of-practice/en/.

5. Regulamento (UE) 2021/382 da Comissão de 3 de março de 2021 que altera os anexos do Regulamento (CE) n.o 852/2004 do Parlamento Europeu e do Conselho relativo à higiene dos géneros alimentícios no que se refere à gestão de alergénios alimentares, à redistribuição dos alimentos e à cultura de segurança dos alimentos. 4p. Disponível em: https://www.flfrevista.pt/file/2021/03/Regulamento_CELEX_32021R0382_PT_TXT.pdf. 6. Food Safety System Certification 22000. (2020). Guidance document: Food safety culture (p.6). p. 6. Disponível em: https://www.fssc22000.com/wp-content/uploads/2020/11/ FSSC-22000-Guidance-Document-Food-Safety-Culture-_Version-5.1.pdf.

7. BRCGS (2018). British Retail Council Global Standard for Food Safety. Issue 8. Disponível em: http://www.brcglobalstandards.com/our-standards/food-safety/.

8. Yiannas F. Food Safety Culture: Creating A Behaviour Based Food Safety Management System. New York, NY.: Springer; 2009.

9. Griffith CJ, Livesey KM, Clayton DA. Food safety culture: the evolution of an emerging risk factor? British Food Journal. 2010;112(4):426-38. Disponível em: https://www. emeraldinsight.com/doi/abs/10.1108/00070701011034439.

10. GFSI. (2018). A culture of food safety - A position paper from the Global Food Safety Initiative (GFSI). Disponível em: https://www.mygfsi.com/files/GFSI_A_Culture_Of_Food_Safety_SUMMARY.pdf.

11. Sharman N, Wallace CA, Jespersen L. Terminology and the understanding of culture, climate, and behavioural change - Impact of organisational and human factors on food safety management. Trends in Food Science \& Technology. 2020;96:13-20. Disponível em: https://www.sciencedirect.com/science/article/abs/pii/S092422441930439X? via\%3Dihub.

12. Coreil J, Bryant C, Henderson JN, Forthofer MS, Quinn GP. Social and Behavioral Foundations of Public Health: SAGE Publications; 2001.

13. Taylor J. An exploration of food safety culture in a multi-cultural environment: next steps? Worldwide Hospitality and Tourism Themes. 201;3(5):455-66. Disponível em: https://www.emeraldinsight.com/doi/abs/10.1108/17554211111185836.

14. Schein EH. Organizational Culture and Leadership: Wiley; 2004.

15. Jespersen L, Griffiths M, Maclaurin T, Chapman B, Wallace CA. Measurement of food safety culture using survey and maturity profiling tools. Food Control. 2016 66:174-82. Disponível em: https://www.sciencedirect.com/science/article/pii/ S0956713516300317?via\%3Dihub.

16. Deal TE, Kennedy AA. Corporate Cultures: The Rites and Rituals of Corporate Life: Addison-Wesley Publishing Company; 1982.

17. Cooper D. Improving Safety Culture: A Practical Guide: Wiley; 1998

18. Dodsworth M, Connelly KE, Ellett CJ, Sharratt P. Organizational Climate Metrics as Safety, Health and Environment Performance Indicators and an Aid to Relative Risk Ranking within Industry. Process Safety and Environmental Protection. 2007; 85(1): 59-69. Disponível em: https://www.sciencedirect.com/science/article/pii/ S0957582007713873?via\%3Dihub.

19. Nyarugwe SP, Linnemann A, Hofstede GJ, Fogliano V, Luning PA. Determinants for conducting food safety culture research. Trends in Food Science \& Technology. 2016;56:77-87. Disponível em: https://www.sciencedirect.com/science/article/abs/ pii/S0924224416300747.

20. Advisory Committee on the Safety of Nuclear Installations (ACSNI). ACSNI Study Group on Human Factors. Third Report: Organising for Safety. United Kingdom: HM Stationery Office; 1993.

21. Cox S, Flin R. Safety culture: Philosopher's stone or man of straw? Work \& Stress. 1998; 12(3):189-201. Disponível em: https://www.tandfonline.com/doi/ abs/10.1080/02678379808256861.

22. Griffith CJ. Developing and Maintaining a Positive Food Safety Culture. Doncaster.: Highfield.co.uk.; 2014

23. Griffith CJ, Livesey KM, Clayton D. The assessment of food safety culture. British Food Journal. 2010;112(4):439-56. Disponível em: https://www.emeraldinsight.com/ doi/abs/10.1108/00070701011034448.

24. Jespersen L, Griffiths M, \& Wallace CA. (2017a). Comparative analysis of existing food safety culture evaluation systems. Food Control, 79, 371-379. Disponível em: https://doi.org/10.1016/j.foodcont.2017.03.037.

25. Taylor J, Garat JP, Simreen S, \& Sarieddine G. (2015). An industry perspective: A new model of Food Safety Culture Excellence and the impact of audit on food safety standards. Worldwide Hospitality and Tourism Themes, 7(1), 78-89. Disponível em: https://doi.org/10.1108/WHATT-12-2014-0041.

26. De Boeck E, Jacxsens L, Bollaerts M, Uyttendaele M, \& Vlerick P. (2016). Interplay between food safety climate, food safety management system and microbiological hygiene in farm butcheries and affiliated butcher shops. Food Control, 65, 78-91. Disponível em: https://doi.org/10.1016/j.foodcont.2016.01.014.

27. Daft RL. Administração: Cengage Learning; 2010.

28. Jacxsens L, Uyttendaele M, Devlieghere F, Rovira J, Gomez SO, Luning PA. Food safety performance indicators to benchmark food safety output of food safety management systems. Int J Food Microbiol. 2010;141 Suppl 1:S180-7. Disponível em: https://www.sciencedirect.com/science/article/pii/S0168160510002618?via\%3Dihub. 29. Luning PA, Marcelis WJ. A conceptual model of food quality management functions based on a techno-managerial approach. Trends in Food Science \& Technology. 2007;18(3):159-66. Disponível em: https://www.sciencedirect.com/science/article/ abs/pii/S0924224406003219.

30. Sampers I, Toyofuku H, Luning PA, Uyttendaele M, Jacxsens L. Semi-quantitative study to evaluate the performance of a HACCP-based food safety management system in Japanese milk processing plants. Food Control. 2012;23(1):227-33. Disponível em: https://www.sciencedirect.com/science/article/pii/S095671351100291X?via\%3Dihub. 31. Kirezieva K, Jacxsens L, Hagelaar GJLF, van Boekel MAJS, Uyttendaele M, Luning PA. Exploring the influence of context on food safety management: Case studies of leafy greens production in Europe. Food Policy. 2015;51:158-70. Disponível em: https://www.sciencedirect.com/science/article/pii/S0306919215000068?via\%3Dihub. 32. Griffith CJ, Redmond E. Good practice for food handlers and consumers. In: Blackburn CdW, McClure PJ, editors. Foodborne Pathogens Hazards, Risk Analysis and Control. Cambridge: Woodhead Publishing; 2009. p. 518-43.

33. Sampers I, Jacxsens L, Luning PA, Marcelis WJ, Dumoulin A, Uyttendaele M. Performance of food safety management systems in poultry meat preparation processing plants in relation to Campylobacter spp. contamination. J Food Prot. 2010;73(8):144757. Disponível em: http://jfoodprotection.org/doi/abs/10.4315/0362-028X-73.8.1447. 34. Luning PA, Jacxsens L, Rovira J, Osés SM, Uyttendaele M, Marcelis WJ. A concurrent diagnosis of microbiological food safety output and food safety management system performance: Cases from meat processing industries. Food Control.;22(3):555-65. Disponível em: https://www.sciencedirect.com/science/article/pii/ S095671351000335X?via\%3Dihub.

35. De Boeck E, Jacxsens L, Bollaerts M, Vlerick P. Food safety climate in food processing organizations: Development and validation of a self-assessment tool. Trends in Food Science \& Technology. 2015;46(2, Part A):242-51. Disponível em: https://www. sciencedirect.com/science/article/abs/pii/S0924224415002150.

36. Ko WH, Kang HY. Effect of leadership style and organizational climate on employees' food safety and hygiene behaviors in the institutional food service of schools. Food Sci Nutr. 2019; 7: 2131-2143. Disponível em: https://doi.org/10.1002/fsn3.1056. 37. Isosaki M, Nakasato M. Gestão de serviço de nutrição hospitalar. São Paulo: Elsevier; 2011.

38. Isosaki M, Cardoso E, Perazzolo E, Omaki CN. Liderança para gestores de nutrição. São Paulo: Atheneu; 2013.

39. Griffith CJ, Jackson LM, Lues R. The food safety culture in a large South African food service complex: Perspectives on a case study. British Food Journal. 2017;119(4):729-43. Disponível em: https://www.emeraldinsight.com/doi/abs/10.1108/BFJ-11-2016-0533. 40. Yiannas F. Food Safety = Behavior: 30 Proven Techniques to Enhance Employee Compliance: Springer New York; 2015.

41. Rosenberg MB. Comunicação não-violenta: técnicas para aprimorar relacionamentos pessoais e profissionais. São Paulo: Ágora.; 2006.

42. Geller ES. Behavior-Based Safety and Occupational Risk Management. Behavior Modification. 2005;29(3):539-61. Disponível em: http://journals.sagepub.com/ doi/10.1177/0145445504273287. 
43. Kane K, Taylor JZ. Integrating culture and management control: is it oil and water or salad dressing? Worldwide Hospitality and Tourism Themes. 2018. Disponível em: https://www.emeraldinsight.com/doi/abs/10.1108/WHATT-02-2018-0014.

44. De Freitas RSG, Da Cunha DT, Stedefeldt E. Work Conditions, Social Incorporations, and Foodborne Diseases Risk: Reflections About the (Non)Compliance of Food Safety Practices. Risk Analysis. 2020. Disponível em: https://onlinelibrary.wiley.com/ doi/full/10.1111/risa.13453.

45. Slovic P. Perception of risk. Science. 1987;236(4799):280-5. Disponível em: http:// science.sciencemag.org/content/236/4799/280/tab-pdf.

46. Lynn F. Risk perception and risk communication about food safety issues. Nutrition Bulletin. 2000;25(1):31-3. Disponível em: https://onlinelibrary.wiley.com/doi/ abs/10.1046/j.1467-3010.2000.00015.x.

47. Dubugras MTB, Pérez-Gutiérrez E. Perspectiva sobre a análise de risco na segurança dos alimentos. Curso de sensibilização. Rio de Janeiro: Área de Vigilância Sanitária, Prevenção e Controle de Doenças - OPAS/OMS; 2008.

48. De Freitas RSG, Da Cunha DT, Stedefeldt E. Food safety knowledge as gateway to cognitive illusions of food handlers and the different degrees of risk perception. Food Research International. 2019; 116:126-34. Disponível em: https://www.sciencedirect. com/science/article/abs/pii/S0963996918310056.

49. Rossi MCS, Stedefeldt E, Cunha DT, Rosso W. Food safety knowledge, optimistic bias and risk perception among food handlers in institutional food services. Food Control. 2017;73:681-8. Disponível em: https://www.sciencedirect.com/science/article/pii/ S0956713516305084?via\%3Dihub.

50. Da Cunha DT, Cipullo MAT, Stedefeldt E, De Rosso W. Food safety knowledge and training participation are associated with lower stress and anxiety levels of Brazilian food handlers. Food Control. 2015;50:684-9. Disponível em: https://www.sciencedirect. com/science/article/pii/S0956713514005945?via\%3Dihubs.

51. Da Cunha DT. Improving food safety practices in the foodservice industry. Current Opinion in Food Science. 2021;42:127-33. Disponível em: https://www.sciencedirect. com/science/article/pii/S2214799321000990.

52. Zanin LM, Stedefeldt E, da Silva SM, da Cunha DT, Luning PA. Influence of educational actions on transitioning of food safety culture in a food service context: Part 2 - Effectiveness of educational actions in a longitudinal study. Food Control. 2021;120:107542. Disponível em: https://www.sciencedirect.com/science/article/ abs/pii/S0956713520304588?via\%3Dihub.

53. Nyarugwe SP, Linnemann AR, Luning PA. Prevailing food safety culture in companies operating in a transition economy - Does product riskiness matter? Food Control. 2020;107:106803. Disponível em: https://www.sciencedirect.com/science/article/pii/ S0956713519303925?via\%3Dihub.

54. Zanin LM, Luning PA, da Cunha DT, Stedefeldt E. Influence of educational actions on transitioning of food safety culture in a food service context: Part 1 Triangulation and data interpretation of food safety culture elements. Food Control. 2021;119:107447. Disponivel em: https://www.sciencedirect.com/science/article/pii/ S0956713520303637?via\%3Dihub. 